OPEN ACCESS

Edited by:

Thomas Lion,

St. Anna Kinderkrebsforschung

(CCRI), Italy

Reviewed by:

Hirokazu Kimura,

Gumma Paz College, Japan Bernhard Resch

Medizinische Universität Graz, Austria

*Correspondence:

Karin Pichler

karin.a.pichler@meduniwien.ac.at

Specialty section:

This article was submitted to

Virology,

a section of the journal

Frontiers in Microbiology

Received: 17 June 2018 Accepted: 28 September 2018 Published: 19 October 2018

Citation:

Pichler K, Assadian O and Berger A (2018) Viral Respiratory Infections in the Neonatal Intensive Care Unit-A

Review. Front. Microbiol. 9:2484.

doi: $10.3389 /$ fmicb.2018.02484

\section{Viral Respiratory Infections in the Neonatal Intensive Care Unit-A Review}

\author{
Karin Pichler ${ }^{1 *}$, Ojan Assadian ${ }^{2}$ and Angelika Berger ${ }^{1}$ \\ ${ }^{1}$ Division of Neonatology, Intensive Care and Neuropediatrics, Department of Pediatrics and Adolescent Medicine, Medical \\ University of Vienna, Vienna, Austria, ${ }^{2}$ Department for Hospital Epidemiology and Infection Control, Medical University of \\ Vienna, Vienna, Austria
}

Although infrequent, respiratory viral infections (RVIs) during birth hospitalization have a significant impact on short- and long-term morbidity in term and preterm neonates. $\mathrm{RVI}$ have been associated with increased length of hospital stay, severe disease course, unnecessary antimicrobial exposure and nosocomial outbreaks in the neonatal intensive care unit (NICU). Virus transmission has been described to occur via health care professionals, parents and other visitors. Most at risk are infants born prematurely, due to their immature immune system and the fact that they stay in the NICU for a considerable length of time. A prevalence of RVIs in the NICU in symptomatic infants of $6-30 \%$ has been described, although RVIs are most probably underdiagnosed, since testing for viral pathogens is not performed routinely in symptomatic patients in many NICUs. Additional challenges are the wide range of clinical presentation of RVIs, their similarity to bacterial infections and the unreliable detection methods prior to the era of molecular biology based technologies. In this review, current knowledge of early-life RVI in the NICU is discussed. Reviewed viral pathogens include human rhinovirus, respiratory syncytial virus and influenza virus, and discussed literature is restricted to reports based on modern molecular biology techniques. The review highlights therapeutic approaches and possible preventive strategies. Furthermore, short- and long-term consequences of RVIs in infants hospitalized in the NICU are discussed.

Keywords: viral respiratory tract infections, neonatal intensive care unit, preterm infant, human rhinovirus, respiratory syncytial virus, human metapneumovirus, influenza virus

\section{INTRODUCTION}

Respiratory viral infections (RVIs) are increasingly recognized to be more prevalent in the neonatal intensive care unit (NICU) than previously considered (Ronchi et al., 2014). So far, RVIs have frequently been undiagnosed or have been identified only late in the course of an infectious episode because of their subtle clinical presentation (Ronchi et al., 2014). If infants presented with clinical deterioration the standard approach in many NICUs usually is to evaluate for bacterial sepsis, but the possibility that a viral pathogen may be the causative agent still is not being considered routinely. The currently established work-up strategy is supported by abundantly available diagnostic methods with a focus on bacterial agents and a still limited diagnostic accuracy with low sensitivity in increasingly available viral point-of care tests based on antigen detection (Casiano-Colón et al., 2003). 
Only the emergence of new diagnostic methods such as the multiplex reverse transcription-polymerase chain reaction enzyme-linked immunosorbent assay (multiplex RT-PCR ELISA) facilitated the identification of virus or virus genome in pediatric patients (Woo et al., 1997; Meerhoff et al., 2010; Krause et al., 2014). PCR based technologies provide results with high sensitivity and specificity and allow screening for a large number of different viruses from a single specimen. Early virus detection is particularly important in the vulnerable infant hospitalized in a NICU. Immediate implementation of effective isolation and infection prevention measures are necessary to prevent further viral transmission, especially in modern, family centered NICUs. These units bear increased risks of virus transmission as they provide kangaroo care, 24 -h visiting policies, and are not only open to parents and siblings, but do also encourage their involvement. Early virus detection also facilitates the withholding or discontinuation of avoidable antimicrobial therapy, contributing to NICU specific stewardship initiatives (Cantey and Patel, 2014). In this review, current knowledge of and literature on early-life RVI in the NICU is discussed on the basis of human rhinovirus, respiratory syncytial virus, and influenza virus. Only original research articles based on modern molecular biology techniques and published in English as well as reporting hospital-acquired RVIs were included.

Anectodal reports have also been published on other than the mentioned viruses such as parainfluenza virus type 3. However, in all of these reports viruses were detected using immunofluorescence techniques (Singh-Naz et al., 1990; Simmonds et al., 2009; Dunn et al., 2017; Maeda et al., 2017). Since this review focuses on reports using PCR-based diagnostics, reports on parainfluenza virus were not included.

\section{Occurrence and Impact of Viral Respiratory Tract Infections}

Although molecular biology based detection methods have already been established 20 years ago, data on the occurrence of RVIs in the NICU is still limited (Ronchi et al., 2014). In infants hospitalized in the NICU and evaluated for late-onset sepsis, the incidence of RVIs was reported to be 6.6-8\% (Ronchi et al., 2014; Cerone et al., 2017; Kidszun et al., 2017). An observational study from the Netherlands found an overall incidence of RVIs in the NICU of around 1\% (Verboon-Maciolek et al., 2005).

Lately, concern of increased nosocomial respiratory virus infection rates arose, because of family centered care and liberalization of visiting policies in NICUs, especially for siblings. Data in this regard are controversial. Some studies noted an increase in symptomatic RVI due to sibling visits (Schwab et al., 1983; Solheim and Spellacy, 1988; Moore et al., 2003; Peluso et al., 2015; Horikoshi et al., 2018). Peluso et al. hypothesized that findings might differ in open-ward NICUs vs. NICUs with single-patient rooms (Peluso et al., 2015), whereas others did not note such an increase. Details on the studies investigating the occurrence of RVIs in the NICU including detected viruses are given in Table 1.

Although the reported incidences seem to be relatively low, relevant short and long-term consequences of early-life RVIs shall be considered (Bennett et al., 2012; Ronchi et al., 2014; Kidszun et al., 2017). Early-life RVIs have been reported to be associated with increased length of hospital stay, severe disease, otherwise avoidable antimicrobial exposure, and nosocomial outbreaks in the NICU (Gelber and Ratner, 2002; Kidszun et al., 2014). A study from the UK reported that $51 \%$ of preterm infants with a RVI needed escalation of respiratory support during the episode with more respiratory pressure support and twice as many required home oxygen. Furthermore, the frequency of broncho-pulmonary dysplasia (BPD) was significantly higher among these infants (Bennett et al., 2012). The majority of patients hospitalized in a NICU, have an immature and inexperienced innate and adaptive immune system (van den Berg et al., 2010). Their innate cytokine response against viruses can be inadequate or, conversely, overwhelming and thus associated with increased disease severity (Perez et al., 2015).

The long-term impact of early-life RVIs is lesser explopored. One study showed an association with lung function abnormalities in susceptible infants, particularly recurrent wheeze and asthma at follow-up at school age (Jackson, 2014). Bennett et al. (2012) reported complications such as longer length of stay and prolonged ventilatory support as well as more than twice the rate of BPD in infants without overt symptoms of RVI but positive virus detection during birth hospitalization. However, it is debatable whether the detection of a virus in nasopharyngeal aspirates truly proves an active respiratory viral infection (Pavia, 2011). Especially viruses like rhinovirus, adenovirus, and enterovirus have frequently been identified in asymptomatic infants (van Benten et al., 2003; Rhedin et al., 2014). Also, during routine surveillance monitoring, respiratory viruses are found in up to $52 \%$ of infants in the NICU (Smit et al., 2013). Thus, it remains unresolved how these findings should be applied to preterm infants during birth hospitalization.

Several studies (Jefferson et al., 2011; Bennett et al., 2012; Kujari et al., 2014; French et al., 2016) reported strategies that aimed to reduce nosocomial RVI in the NICU. The most effective infection prevention practices proved to be cohorting of infected patients, staff protective equipment such as gowns and gloves, hand hygiene policies and restriction of visitors during periods of high community RVI prevalence. However, the majority of these infection prevention measures have been implemented during outbreak situations, and the effect of single measures was never explored systematically in prospective controlled studies. It must, however, be acknowledged that designing prospective studies investigating the preventive efficacy of one single intervention in the clinical practice of a NICU comes with practical and ethical limitations.

\section{Influenza}

Influenza virus infections have long been thought to be uncommon in neonates due to the presence of maternal antibodies (Puck et al., 1980) and the fact that neonates generally have reduced contact with adults or children infected with influenza virus (Wilkinson et al., 2006). However, there is an increasing number of reports on influenza infections in neonates and descriptions of influenza spread within neonatal units. Importantly, cases of severe influenza and mortality in 
TABLE 1 | Studies investigating the occurrence of RVIs in the NICU (LOS, late onset sepsis; RSV, respiratory syncytial virus; HRV, human rhinovirus; LOS, late-onset sepsis; NICU, neonatal intensive care unit; RTVI, respiratory tract viral infection; PMA, post menstrual age).

\begin{tabular}{|c|c|c|c|c|}
\hline Study & Study group & $\begin{array}{l}\text { Duration of } \\
\text { the study }\end{array}$ & $\begin{array}{l}\text { Prevalence } \\
\text { (virus-positive/examined } \\
\text { individuals) }\end{array}$ & Detected viruses \\
\hline $\begin{array}{l}\text { Cerone et al., } 2017 \text {, } \\
\text { USA }\end{array}$ & All infants evaluated for LOS & 26 month & $\begin{array}{l}\text { 29/357 (8\%), } 3 \text { infants were } \\
\text { co-infected with more than } \\
\text { one virus }\end{array}$ & $\operatorname{RSV}(n=14), \operatorname{HRV}(n=11)$, others $(n=7)$ \\
\hline $\begin{array}{l}\text { Kidszun et al., } 2017 \text {, } \\
\text { Germany }\end{array}$ & All infants evaluated for LOS & 43 month & $6 / 137$ (6.8\%) & Picornavirus $(n=4), \operatorname{RSV}(n=2)$ \\
\hline $\begin{array}{l}\text { Caserta et al., } 2017 \text {, } \\
\text { USA }\end{array}$ & $\begin{array}{l}\text { All infants in the NICU }<36 \\
\text { weeks PMA }\end{array}$ & 2 month & $\begin{array}{l}\text { 4/618 (0.6\%), 50\% } \\
\text { asymptomatic }\end{array}$ & $\begin{array}{l}\operatorname{RSV}(n=1), \operatorname{HRV}(n=1), \text { coronavirus } 4 \\
(n=1), \text { Influenza B }(n=1)\end{array}$ \\
\hline $\begin{array}{l}\text { Zinna et al., 2016, } \\
\text { UK }\end{array}$ & $\begin{array}{l}\text { Retrospective case-control study } \\
\text { of infants with PCR positive RVI }\end{array}$ & 6 years & $95 / 275$ & $\begin{array}{l}\text { HRV }(n=65), \text { parainfluenza virus type } 3 \\
(n=6), \operatorname{RSV}(n=5), \text { others }(n=19)\end{array}$ \\
\hline $\begin{array}{l}\text { Kidszun et al., 2014, } \\
\text { Germany }\end{array}$ & All infants evaluated for LOS & 19 month & $6 / 60(10 \%)$ & Picornavirus $(n=5), \operatorname{RSV}(n=1)$ \\
\hline $\begin{array}{l}\text { Ronchi et al., 2014, } \\
\text { USA }\end{array}$ & All infants evaluated for LOS & 12 month & 8/100 (8\%) & $\begin{array}{l}\text { Entero-/rhinoviruses }(n=2), \operatorname{HRV}(n=2) \text {, } \\
\text { coroncavirus }(n=2), \text { parainfluenza viruses } \\
(n=2)\end{array}$ \\
\hline $\begin{array}{l}\text { Bennett et al., 2012, } \\
\text { USA }\end{array}$ & $\begin{array}{l}\text { All infants in the NICU }<33 \\
\text { weeks PMA }\end{array}$ & 12 month & $\begin{array}{l}26 / 50(52 \%), 30 \% \\
\text { asymptomatic }\end{array}$ & $\begin{array}{l}\text { Parainfluenza viruses }(n=20), \operatorname{RSV}(n=15) \text {, } \\
\text { metapneumovirus }(n=9) \text {, others }(n=11)\end{array}$ \\
\hline $\begin{array}{l}\text { Diniz et al., 2005, } \\
\text { Portugal }\end{array}$ & $\begin{array}{l}\text { Infants with acute respiratory } \\
\text { failure and need of mechanical } \\
\text { ventilation }<37 \text { weeks PMA }\end{array}$ & 2 years & 23/78 (29.5\%) & $\begin{array}{l}\text { RSV }(n=11) \text {, influenza A }(n=8) \text {, co-infection } \\
\text { with } 2 \text { viruses }(n=4)\end{array}$ \\
\hline
\end{tabular}

the newborn and especially the preterm infant have also been reported (Wilkinson et al., 2006; Sert et al., 2010).

Influenza is an RNA virus of the Orthomyxoviridae family, classified into types A, B, and C. Influenza type A is responsible for most clinical infection in humans, whereas type B accounts only for $11 \%$ of human infections and type C causes only mild illness (Woods and Abramson, 2005). Transmission occurs mainly by aerosol. Transmission by large droplets and selfinoculation of the nasal mucosa by contaminated hands has also been described several times (Tellier, 2009). The incubation period of influenza ranges from 1 to 5 days. Viral shedding occurs 1 day before clinical symptoms appear through the duration of the symptomatic period (Gelber and Ratner, 2002). Protection and treatment are limited in neonates and especially preterm infants (Whitley and Monto, 2006) as current influenza vaccines are not effective in infants under 6 month of age (Principi and Esposito, 2004). An important prevention method is annual vaccination against influenza of parents, other caregivers and health care workers. However, low compliance, particularly in health care workers, has been repeatedly reported (Kassianos et al., 2018) also among health care workers in the NICU (Milupi et al., 2012; Tsagris et al., 2012). Thus, infected NICU staff may be the source of nosocomial outbreaks, particularly during the early onset phase of the infection and when pressure to present at work is high during critically staffed periods. Despite the obviously possible vicious circle of low immunization rate among healthcare workers-increased likelihood of influenza infection-decreased staffing-increased pressure to present at work even when prodromal symptoms start, we did not identify epidemiological work focusing on the effect of these interconnections.
In the era of PCR-based detection methods 5 outbreaks of influenza have been reported in NICUs (Table 2) (Rocha et al., 2010; Pannaraj et al., 2011; Vij et al., 2011; Milupi et al., 2012; Tsagris et al., 2012). All these outbreaks occurred during the 2009-2010 H1N1 pandemic and reported influenza $\mathrm{A} / \mathrm{H} 1 \mathrm{N1} / 2009$ as causing virus. The affected infants presented mainly with respiratory symptoms including desaturation, tachypnea, increased secretions, apnea and need for mechanical ventilation. Additionally bradycardia, pyrexia, and rales were observed. Such clinical features may be difficult to distinguish from bacterial sepsis. One infant was reported to develop clinical seizures during infection with influenza A/H1N1/2009 (Vij et al., 2011). This infant was born at 29 weeks postmenstrual age (PMA) and was 21 days old at the onset of influenza infection. Because of the seizures a cerebrospinal fluid analysis was performed with normal results. However, it was not sent for influenza A/H1N1/2009 PCR. Also, a cranial MRI did not reveal any abnormalities and the patient fully recovered from the influenza infection. Seizures have been described in association with influenza infections in older children along with neurologic manifestations including encephalopathy (Ekstrand et al., 2010; Kedia et al., 2011).

Next to these outbreak descriptions there are a few case reports on influenza infections in infants hospitalized in the NICU. A publication from Israel reports on a preterm infant of 32 weeks PMA, who developed respiratory failure on day of life 50 due to Influenza A/H1N1. The infant received the neuraminidase inhibitor oseltamivir in therapeutic dosage and was discharged in good health at day of life 60 (Barak et al., 2010). In contrast, Jajoo et al. from India published a case of a preterm infant of 32 weeks PMA who presented with respiratory failure on day 


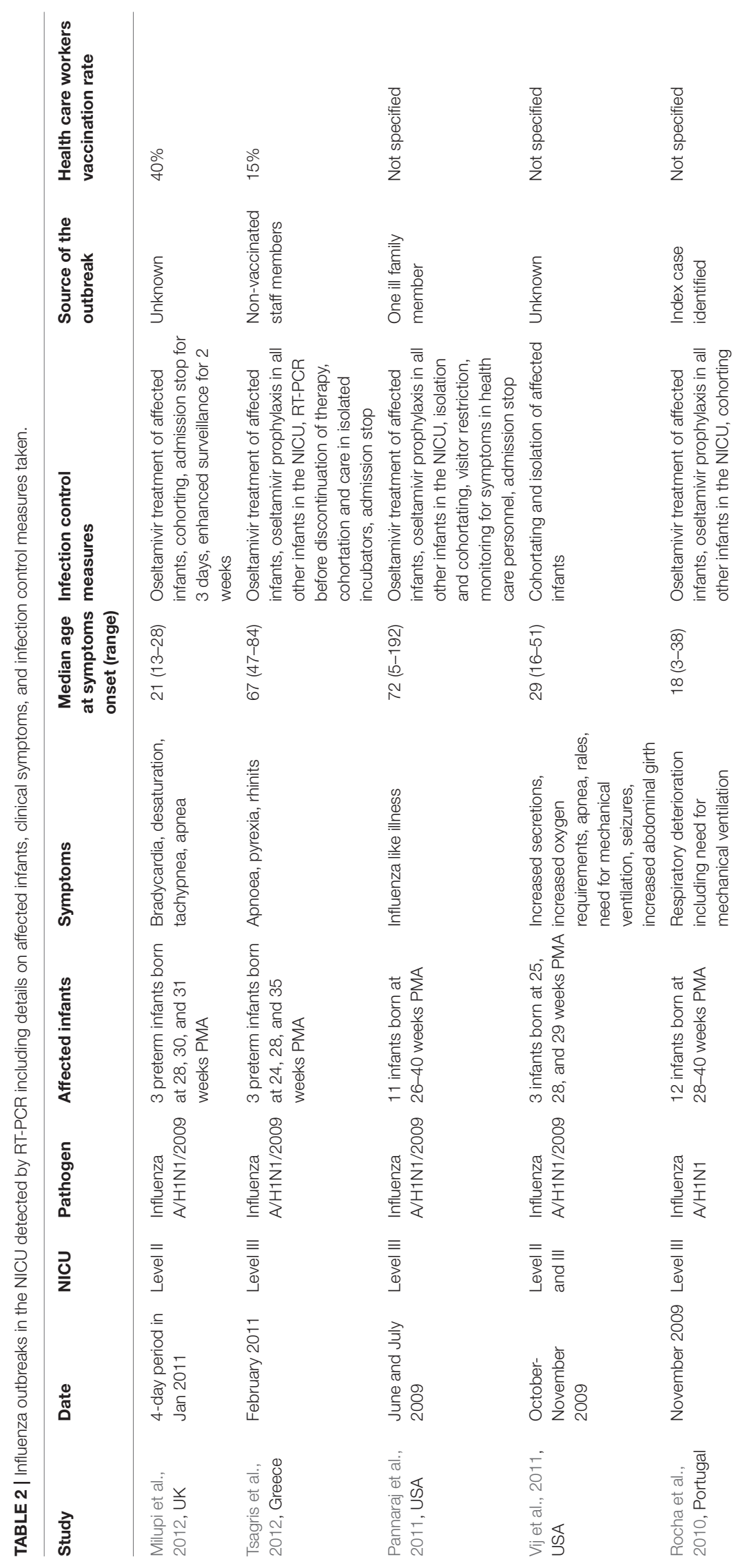


of life 6. The infant was diagnosed with influenza $\mathrm{A} / \mathrm{H} 1 \mathrm{~N} 1$ on day of life 10 and oseltamivir was started in therapeutic dosage. Nevertheless, the infants' pneumonia continued to worsen and the infant died on day of life 16 due to refractory shock and multiorgan dysfunction (Jajoo and Gupta, 2010). To the best of our knowledge this is the only infant reported to have died in the NICU due to influenza A infection, whereas all other reported infants recovered fully from the infection. This is in contrast to reports in other healthcare settings and older patients, where epidemic and pandemic influenza was associated with significant mortality in infants (Bhat et al., 2005). The reason for the relatively low mortality of infants affected from influenza in the NICU is unclear. An important fact might be increased awareness of NICU staff especially in times of pandemics and consecutively early diagnosis and prompt initiation of supportive therapy.

In most of the reported outbreaks and also in the case reports of influenza infection in the NICU, the affected infants were treated with the neuraminidase inhibitor oseltamivir (Bhat et al., 2005; Jajoo and Gupta, 2010; Rocha et al., 2010; Pannaraj et al., 2011; Milupi et al., 2012; Tsagris et al., 2012). Exposed infants commonly received oseltamivir prophylaxis (Rocha et al., 2010; Pannaraj et al., 2011; Milupi et al., 2012; Tsagris et al., 2012). In one NICU outbreak scenario infants diagnosed with influenza were only cohorted and isolated without any drug treatment. Also these infants had a favorable outcome (Vij et al., 2011).

Oseltamivir is a neuraminidase inhibitor effective against both influenza A and B. It is converted to its active metabolite, oseltamivir carboxylate by hepatic esterases and then renally eliminated through both glomerular filtration and tubular secretion processes. These processes are diminished in neonates and young adults and do not reach adult capacity until 6-12 months of age (Abdel-Rahman et al., 2011). Oseltamivir has been shown to reduce the duration of illness in previously healthy children by $26 \%$ ( $36 \mathrm{~h}$; Matheson et al., 2007). Furthermore, it significantly reduced complications of influenza, particularly otitis media. Safety concerns about the use of neuraminidase inhibitors in infants have been raised after an animal trial conducted by the US Food and Drug Administration (Wooltorton, 2004). In this trial 7-day old rats were fed with excessively high doses of oseltamivir ( $\sim 250$ times the dose recommended in children). Many of the rats died consecutively. Nevertheless in 2009 during the H1N1 pandemic, the U.S. Food and Drug Administration released an Emergency Use Authorization (EUA) for oseltamivir in infants $<1$ year of age. The recommendation for dosage was initially age-dependent and was then corrected to a weight-based dosing approach, i.e., $3 \mathrm{mg} / \mathrm{kg} / \mathrm{dose}$ orally twice daily for children 0 to $<12$ month based on the CASG (collaborative Antiviral Study Group of the National Institutes of Health NIH, USA) study results. Acosta et al. subsequently conducted a study to determine the dosing in preterm infants (Acosta et al., 2010). Results from this study suggest a therapeutic oseltamivir dosage of $\sim 1 \mathrm{mg} / \mathrm{kg} / \mathrm{dose}$ twice daily as well as a prophylactic oseltamivir dosage of $\sim 1 \mathrm{mg} / \mathrm{kg} /$ dose once a day in premature neonates $<37$ weeks PMA (Acosta et al., 2010). Both treatment and prophylaxis with oseltamivir must be started within $48 \mathrm{~h}$ of the onset of symptoms or of exposure to be effective (Munoz, 2003; Matheson et al., 2007). In both outbreak reports and case reports where oseltamivir was used in therapeutic and/or prophylactic dose, no serious side effects, especially no central nervous system toxicity was observed (Bhat et al., 2005; Jajoo and Gupta, 2010; Rocha et al., 2010; Pannaraj et al., 2011; Vij et al., 2011; Milupi et al., 2012; Tsagris et al., 2012). Only mild gastrointestinal symptoms like diarrhea were reported. Laboratory investigations monitoring hematology, renal, and hepatic functions were not altered due to therapy with oseltamivir. Thus, oseltamivir in the currently recommended dosage seems to be safe also in the smallest infants and can be considered as therapeutic option during outbreak situations in the NICU.

\section{Human Rhinovirus}

Human rhinovirus (HRV) is among the most frequent causes of upper and lower respiratory tract infections in infants hospitalized in the NICU (van Piggelen et al., 2010; Steiner et al., 2012). HRV is classified into 3 species, A, B and C, within the genus Enterovirus of the Picornaviridae family. More than 150 different HRV genotypes are known so far. HRV infections do not provide protective immunity against other genotypes because of a low cross-neutralization between serotypes (Jacobs et al., 2013). This might be an explanation for the frequent occurrence of HRV infections. Rhinovirus species $\mathrm{C}$ has been associated with more severe illness in several reports, especially in preterm infants, compared to species A or B (Reid et al., 2011; Marcone et al., 2018). Treatment of HRV infection is limited to symptomatic treatment.

Five reports on HRV outbreaks in hospitalized NICU patients have been identified (Table 3). HRV species C was detected as causative agent in three of these reports (Reid et al., 2011; Reese et al., 2016; Marcone et al., 2018), whereas in the other two HRV species was not elucidated due to lack of genotyping (van Piggelen et al., 2010; Steiner et al., 2012). HRV affected both term and preterm infants. Mean age at onset of symptoms was 58 days (range 5-282 days). The most frequent symptoms were nasal congestion, increased respiratory secretions and increased work of breathing. Almost all reported infants needed increased respiratory support and increased oxygen supplementation during the course of the HRV infection (van Piggelen et al., 2010; Reid et al., 2011; Steiner et al., 2012; Reese et al., 2016; Marcone et al., 2018). In the report of van Piggelen et al. from the Netherlands (van Piggelen et al., 2010), which included 11 patients of 26-41 weeks PMA, all infants needed mechanical ventilation during the infectious episode. Generally, severe respiratory failure due to HRV infection does not seem to be uncommon (Reid et al., 2011; Steiner et al., 2012; Reese et al., 2016; Marcone et al., 2018) and has been described even in an otherwise healthy term newborn (Broberg et al., 2011). In contrast, all patients requiring mechanical ventilation during HRV infection in the report of Steiner et al. had major comorbidities besides prematurity (giant thoracic lymphangioma, neuromuscular impairment owing to severe perinatal asphyxia and to suspected metabolic disorder, respectively; Steiner et al., 2012). Furthermore, Steiner et al. reported that presence of 
apneas during HRV infection correlated with a more severe disease course (Steiner et al., 2012).

All infants reported in the literature recovered from HRV infection. One study (van Piggelen et al., 2010) reported that 4 infants developed recurrent respiratory tract infections in the first year of life, which, according to the authors, could not be explained solely by prematurity. No other data is available on possible long-term consequences of HRV infection in this early period of life.

Also, only limited data exists about nosocomial HRV transmission (Reid et al., 2011; Reese et al., 2016; Marcone et al., 2018). It is known that HRV can remain viable from hours to days on environmental surfaces at ambient temperature. Thus, transmission can occur both via direct contact or aerosolization (Jacobs et al., 2013). A further challenge of HRV is that virus shedding has been reported to occur up to 44 days in otherwise healthy preterm infants (Steiner et al., 2012; Marcone et al., 2018). Management of these infants with a positive PCR result but resolved clinical signs in the NICU is problematic. To date there are no studies correlating viral loads with either infectiousness or the presence of infectious viral particles.

\section{Respiratory Syncytial Virus (RSV)}

RSV is an enveloped, non-segmented, negative-sense RNA virus belonging to the Pneumoviridae family and is classified in the genus orthopneumovirus. It is divided into two antigenic subgroups, A and B. RSV is the leading cause of hospitalization for respiratory illness in children under 12 month of age (Iwane et al., 2004). It causes seasonal outbreaks worldwide. Symptoms of RSV infection range from afebrile cough and congestion to severe bronchiolitis or pneumonia with respiratory failure. Most at risk for severe RSV infection are infants aged $<6$ months, preterm infants born prior to 35 weeks PMA and infants and children with underlying lung disease or congenital heart disease (Boyce et al., 2000). Some studies reported more severe disease courses in RSV subtype A infections as compared to subytpe B (Halasa et al., 2005; Buonocore et al., 2012).

RSV spreads by close contact via direct inoculation of largeparticle aerosols or self-inoculation after touching contaminated surfaces. RSV is also able to spread hemtogenously from the primary site of infection to remote extra-pulmonary tissue (Eisenhut, 2006). The virus replicates in the nasal or ocular mucosal epithelium (Goldmann, 2000). Although RSV is relatively labile, the virus can survive for $6-12 \mathrm{~h}$ on surfaces, providing the opportunity for environmental nosocomial transmission. Homaira et al. examined clothing of health care workers and visitors as potential source of RSV infection in the NICU and detected RSV-RNA only at a low viral load on clothing of health care workers (Homaira et al., 2016). An older study found that freshly obtained secretions from infected infants survive on clothing of health care workers for $\sim 40 \mathrm{~min}$ (Hall et al., 1980). Thus, carriage on clothing may contribute to nosocomial infections in the NICU.

RSV detection rates in NICUs in the absence of outbreaks seem to be low. Studies indicated rates from 1 to $4 \%$ during winter epidemics (Berger et al., 2010; Homaira et al., 2016). However, nosocomial RSV infections have been reported to cause

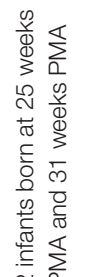


more severe courses than community acquired RSV infections (Simon et al., 2008) and lead to high morbidity, significant mortality and substantial increase in health care costs (Halasa et al., 2005). There is a limited number of reports in the literature on nosocomially acquired RSV infections among both term and preterm infants in the NICU (Bont, 2009). Four NICU outbreaks of RSV were reported using RT-PCR technology for virus detection (Halasa et al., 2005; Visser et al., 2008; O'Connell et al., 2011; Hammoud et al., 2016; Table 4). In all these reports infants presented with signs of respiratory deterioration and need of increased respiratory support. In general, RSV infections in the NICU occurred mostly late in the clinical course, i.e., with a mean age of more than one month (Table 4). However, individual infections as early as on day 10 of life were reported (Table 4). Many infants needed mechanical ventilation in the course of the RSV infection. One case was reported to require extracorporal membrane oxygenation (ECMO; Halasa et al., 2005). Still, most infants recovered from the RSV infection. In the study of Berger et al. (2010) patients, parents and staff were screened for RSV in a NICU for a period of 8 weeks. Only 4 of 1,002 samples tested positive for RSV. The only infant, however, diagnosed with RSV infection in this study had a fatal outcome. This infant was a preterm 26 weeks PMA infant with first symptoms of RSV infection on day of life 42 after an uneventful clinical course, which emphasizes the risk of an adverse outcome of nosocomial RSV infections especially in premature infants. Also in the study of Visser et al. which reports an outbreak of RSV in a South African kangaroo mother care unit, 2 infants died due to a fatal course of RSV infection. Both patients were male and born at 28 and 32 weeks PMA, respectively. The first child suffered from a dual infection with RSV A and B while the second was infected with RSV B (Visser et al., 2008).

Because of the high mortality and morbidity reported in special patient groups, prophylactic immunization with palivizumab is recommended monthly during the RSV season (Simoes, 1999; American Academy of Pediatrics Bronchiolitis Guidelines Committee, 2014). Palivizumab is a monoclonal antibody that is usually administered prior to hospital discharge to be protective against community-acquired RSV infection (American Academy of Pediatrics Bronchiolitis Guidelines Committee, 2014). If administered correctly, palivizumab has been shown to be safe and effective in reducing the number of RSV-related hospitalization in randomized, multicenter, placebo-controlled trials (1998; Wegzyn et al., 2014). Also, in the reported outbreak scenarios the authors chose to administer palivizumab either to all infants hospitalized in the NICU (O'Connell et al., 2011; Hammoud et al., 2016) or to a subgroup of NICU patients who were considered to be at particularly increased risk of nosocomial RSV infection (Halasa et al., 2005) and reported successful termination of the outbreak. Despite these anecdotal reports, immunoprophylaxis with palivizumab is currently not recommended for the prevention of health care-associated RSV infections (American Academy of Pediatrics Bronchiolitis Guidelines Committee, 2014).

Several authors highlight that of all infection control methods, adequate hand washing/hand disinfection, rapid screening for 
infection and cohorting of infected patients are most effective to prevent RSV transmission in NICUs and pediatric wards (Groothuis et al., 2008).

\section{CONCLUSION}

RVIs are still an under-diagnosed and underestimated entity in the NICU. Although incidences of RVIs are relatively low and outbreaks are rare, RVIs can cause significant morbidity in neonates and especially preterm infants. Thus, PCR based virus detection methods should be considered in infants hospitalized in the NICU with signs of respiratory deterioration in order to allow rapid diagnosis of RVIs and to implement rapidly effective

\section{REFERENCES}

(1998). Palivizumab, a humanized respiratory syncytial virus monoclonal antibody, reduces hospitalization from respiratory syncytial virus infection in high-risk infants. The impact-rsv study group. Pediatrics 102(3 Pt 1):531-7.

Abdel-Rahman, S. M., Newland, J. G., and Kearns, G. L. (2011). Pharmacologic considerations for oseltamivir disposition: focus on the neonate and young infant. Paediatr Drugs 13, 19-31. doi: 10.2165/11536950-00000000000000

Acosta, E. P., Jester, P., Gal, P., Wimmer, J., Wade, J., Whitley, R. J., et al. (2010). Oseltamivir dosing for influenza infection in premature neonates. J. Infect. Dis. 202, 563-566. doi: $10.1086 / 654930$

American Academy of Pediatrics Bronchiolitis Guidelines Committee (2014). Updated guidance for palivizumab prophylaxis among infants and young children at increased risk of hospitalization for respiratory syncytial virus infection. Pediatrics 134, 415-420. doi: 10.1542/peds. 2014-1665

Barak, S., Kushnir, A., Chulski, E., and Miron, D. (2010). Influenza A/H1N1 virus in very low-birth-weight premature infant: case report. Am. J. Perinatol. 27, 513-515. doi: 10.1055/s-0030-1247606

Bennett, N. J., Tabarani, C. M., Bartholoma, N. M., Wang, D., Huang, D., Riddell, S. W., et al. (2012). Unrecognized viral respiratory tract infections in premature infants during their birth hospitalization: a prospective surveillance study in two neonatal intensive care units. J. Pediatr. 161, 814-818. doi: 10.1016/j.jpeds.2012.05.001

Berger, A., Obwegeser, E., Aberle, S. W., Langgartner, M., and Popow-Kraupp, T. (2010). Nosocomial transmission of respiratory syncytial virus in neonatal intensive care and intermediate care units: a prospective epidemiologic study. Pediatr. Infect. Dis. J. 29, 669-670. doi: 10.1097/INF.0b013e3181d76d61

Bhat, N., Wright, J. G., Broder, K. R., Murray, E. L., Greenberg, M. E., Glover, M. J., et al. (2005). Influenza-associated deaths among children in the united states, 2003-2004. N. Engl. J. Med. 353, 2559-2567. doi: 10.1056/NEJMoa051721

Bont, L. (2009). Nosocomial RSV infection control and outbreak management. Paediatr. Respir. Rev. 10(Suppl. 1):16-17. doi: 10.1016/S1526-0542(09)70008-9

Boyce, T. G., Mellen, B. G., Mitchel, E. F., Wright, P. F., and Griffin, M. R. (2000). Rates of hospitalization for respiratory syncytial virus infection among children in medicaid. J. Pediatr. 137, 865-870. doi: 10.1067/mpd.2000.110531

Broberg, E., Niemel,ä, J., Lahti, E., Hyypiä, T., Ruuskanen, O., and Waris, M. (2011). Human rhinovirus c-associated severe pneumonia in a neonate. J. Clin. Virol. 51, 79-82. doi: 10.1016/j.jcv.2011.01.018

Buonocore, G., Bracci, R., and Weindling, A. M. (2012). Neonatology: A Practical Approach to Neonatal Diseases. Milan: Springer.

Cantey, J. B., and Patel, S. J. (2014). Antimicrobial stewardship in the NICU. Infect. Dis. Clin. North Am. 28, 247-261. doi: 10.1016/j.idc.2014.01.005

Caserta, M. T., Yang, H., Gill, S. R., Holden-Wiltse, J., and Pryhuber, G. (2017). Viral respiratory infections in preterm infants during and after hospitalization. J. Pediatr. 182, 53.e3-58.e3. doi: 10.1016/j.jpeds.2016.11.077

Casiano-Colón, A. E., Hulbert, B. B., Mayer, T. K., Walsh, E. E., and Falsey, A. R. (2003). Lack of sensitivity of rapid antigen tests for the diagnosis of isolation and infection prevention measures to prevent both severe disease in theses infants and viral spread in the unit.

\section{AUTHOR CONTRIBUTIONS}

$\mathrm{KP}$ and OA performed the review of the current literature as well as data analysis. KP and AB drafted the manuscript. All authors have read and approved the final manuscript.

\section{ACKNOWLEDGMENTS}

We acknowledge Ms. Brigitte Wildner for her valuable help in literature search. respiratory syncytial virus infection in adults. J. Clin. Virol. 28, 169-174. doi: 10.1016/S1386-6532(03)00002-7

Cerone, J. B., Santos, R. P., Tristram, D., Lamson, D. M., Stellrecht, K. A., St George, K., et al. (2017). Incidence of respiratory viral infection in infants with respiratory symptoms evaluated for late-onset sepsis. J. Perinatol. 37, 922-926. doi: 10.1038/jp.2017.69

Diniz, E. M., Vieira, R. A., Ceccon, M. E., Ishida, M. A., and Vaz, F. A. (2005). Incidence of respiratory viruses in preterm infants submitted to mechanical ventilation. Rev. Inst. Med. Trop. Sao. Paulo 47, 37-44. doi: 10.1590/S0036-46652005000100007

Dunn, G. L., Tapson, H., Davis, J., and Gobin, M. (2017). Outbreak of piv-3 in a neonatal intensive care unit in England. Pediatr. Infect. Dis. J. 36, 344-345. doi: 10.1097/INF.0000000000001443

Eisenhut, M. (2006). Extrapulmonary manifestations of severe RSV bronchiolitis. Lancet 9540:988. doi: 10.1016/S0140-6736(06)69409-9

Ekstrand, J. J., Herbener, A., Rawlings, J., Turney, B., Ampofo, K., Korgenski, E. K., et al. (2010). Heightened neurologic complications in children with pandemic H1N1 influenza. Ann. Neurol. 68, 762-766. doi: 10.1002/ana.22184

French, C. E., McKenzie, B. C., Coope, C., Rajanaidu, S., Paranthaman, K., Pebody, R., et al. (2016). Risk of nosocomial respiratory syncytial virus infection and effectiveness of control measures to prevent transmission events: a systematic review. Influenza Other Respir. Viruses 10, 268-290. doi: 10.1111/irv.1 2379

Gelber, S. E., and Ratner, A. J. (2002). Hospital-acquired viral pathogens in the neonatal intensive care unit. Semin. Perinatol. 26, 346-356. doi: $10.1053 /$ sper.2002.36268

Goldmann, D. A. (2000). Transmission of viral respiratory infections in the home. Pediatr. Infect. Dis. J. 19(Suppl. 10), S97-S102. doi: 10.1097/00006454-200010001-00002

Groothuis, J., Bauman, J., Malinoski, F., Eggleston, M. (2008). Strategies for prevention of RSV nosocomial infection. J. Perinatol. 28, 319-23. doi: $10.1038 /$ jp. 2008.37

Halasa, N. B., Williams, J. V., Wilson, G. J., Walsh, W. F., Schaffner, W., and Wright, P. F. (2005). Medical and economic impact of a respiratory syncytial virus outbreak in a neonatal intensive care unit. Pediatr. Infect. Dis. J. 24, 1040-1044. doi: 10.1097/01.inf.0000190027.59795.ac

Hall, C. B., Douglas, R. G., and Geiman, J. M. (1980). Possible transmission by fomites of respiratory syncytial virus. J. Infect. Dis. 141, 98-102. doi: 10.1093/infdis/141.1.98

Hammoud, M. S., Al-Taiar, A., Raina, A., Elsori, D., Al-Qabandi, S., and Al-Essa, M. (2016). Use of palivizumab with other infection control measures to control respiratory syncytial virus outbreaks in neonatal care units. J. Trop. Pediatr. 62, 409-414. doi: 10.1093/tropej/fmw025

Homaira, N., Sheils, J., Stelzer-Braid, S., Lui, K., Oie, J. L., Snelling, T., et al. (2016). Respiratory syncytial virus is present in the neonatal intensive care unit. J. Med. Virol. 88, 196-201. doi: 10.1002/jmv.24325

Horikoshi, Y., Okazaki, K., Miyokawa, S., Kinoshita, K., Higuchi, H., Suwa, J., et al. (2018). Sibling visits and viral infection in the neonatal intensive care unit. Pediatr. Int. 60, 153-156. doi: 10.1111/ped.13470 
Iwane, M. K., Edwards, K. M., Szilagyi, P. G., Walker, F. J., Griffin, M. R., Weinberg, G. A., et al. (2004). Populationbased surveillance for hospitalizations associated with respiratory syncytial virus, influenza virus, and parainfluenza viruses among young children. Pediatrics 113, 1758-1764. doi: 10.1542/peds.113. 6.1758

Jackson, D. J. (2014). Early-life viral infections and the development of asthma: a target for asthma prevention? Curr. Opin. Allergy Clin. Immunol. 14, 131-136. doi: 10.1097/ACI.0000000000000047

Jacobs, S. E., Lamson, D. M., St George, K., and Walsh, T. J. (2013). Human rhinoviruses. Clin. Microbiol. Rev. 26, 135-162. doi: 10.1128/CMR.00077-12

Jajoo, M., and Gupta, R. (2010). H1N1 influenza in a preterm neonate. Indian J. Pediatr. 77, 1045-1046. doi: 10.1007/s12098-010-0166-2

Jefferson, T., Del Mar, C. B., Dooley, L., Ferroni, E., Al-Ansary, L. A., Bawazeer, G. A., et al. (2011). Physical interventions to interrupt or reduce the spread of respiratory viruses. Cochrane Database Syst. Rev. 6:CD006207. doi: 10.1002/14651858.CD006207.pub4

Kassianos, G., Kuchar, E., Nitsch-Osuch, A., Kyncl, J., Galev, A., Humolli, I., et al. (2018). Motors of influenza vaccination uptake and vaccination advocacy in healthcare workers: a comparative study in six european countries. Vaccine 28, 6546-6552. doi: 10.1016/j.vaccine.2018.02.031

Kedia, S., Stroud, B., Parsons, J., Schreiner, T., Curtis, D. J., Bagdure, D., et al. (2011). Pediatric neurological complications of 2009 pandemic influenza A (H1N1). Arch. Neurol. 68, 455-462. doi: 10.1001/archneurol.2010.318

Kidszun, A., Hansmann, A., Winter, J., Gröndahl, B., Knuf, M., Weise, K., et al. (2014). Detection of respiratory viral infections in neonates treated for suspicion of nosocomial bacterial sepsis: a feasibility study. Pediatr. Infect. Dis. J. 33, 102-104. doi: 10.1097/INF.0000000000000008

Kidszun, A., Klein, L., Winter, J., Schmeh, I., Gröndahl, B., Gehring, S., et al. (2017). Viral infections in neonates with suspected late-onset bacterial sepsis-a prospective cohort study. Am. J. Perinatol. 34, 1-7. doi: $10.1055 / \mathrm{s}-0036-1584150$

Krause, J. C., Panning, M., Hengel, H., and Henneke, P. (2014). The role of multiplex PCR in respiratory tract infections in children. Dtsch. Arztebl. Int. 111, 639-645. doi: 10.3238/arztebl.2014.0639

Kujari, A. M., Waris, M., Lehtonen, L., and Ruuskanen, O. (2014). Respiratory viral infections are not uncommon in neonatal intensive care units. Acta Paediatr. 103, e225-e228. doi: 10.1111/apa.12590

Maeda, H., Haneda, K., and Honda, Y. (2017). Parainfluenza virus type 3 outbreak in a neonatal intensive care unit. Pediatr. Int. 59, 1219-1222. doi: $10.1111 /$ ped.13389

Marcone, D. N., Carballal, G., Irañeta, M., Rubies, Y., Vidaurreta, S. M., and Echavarría, M. (2018). Nosocomial transmission and genetic diversity of rhinovirus in a neonatal intensive care unit. $J$ Pediatr. 193, 252.e1-255.e1. doi: 10.1016/j.jpeds.2017.09.013

Matheson, N. J., Harnden, A. R., Perera, R., Sheikh, A., and SymmondsAbrahams, M. (2007). Neuraminidase inhibitors for preventing and treating influenza in children. Cochrane Database Syst. Rev. 24:CD002744. doi: 10.1002/14651858.CD002744.pub2

Meerhoff, T. J., Houben, M. L., Coenjaerts, F. E., Kimpen, J. L., Hofland, R. W., Schellevis, F., et al. (2010). Detection of multiple respiratory pathogens during primary respiratory infection: nasal swab versus nasopharyngeal aspirate using real-time polymerase chain reaction. Eur. J. Clin. Microbiol. Infect. Dis. 29, 365-371. doi: 10.1007/s10096-009-0865-7

Milupi, M., Madeo, M., Brooke, N., and Ahmad, S. J. (2012). Neonatal influenza $\mathrm{A} / \mathrm{H} 1 \mathrm{~N} 1 / 2009$ outbreak in a UK district general hospital. J. Hosp. Infect. 81, 131-133. doi: 10.1016/j.jhin.2012.04.005

Moore, K. A., Coker, K., Du Buisson, A. B., Swett, B., and Edwards, W. H. (2003), Implementing potentially better practices for improving family-centered care in neonatal intensive care units: successes and challenges. Pediatrics $111(4 \mathrm{Pt}$ 2), e450-e 460

Munoz, F. M. (2003). Influenza virus infection in infancy and early childhood. Paediatr. Respir. Rev. 4, 99-104. doi: 10.1016/S1526-0542(03)00027-7

O’Connell, K., Boo, T. W., Keady, D., Niriain, U., O’Donovan, D., Commane, M., et al. (2011). Use of palivizumab and infection control measures to control an outbreak of respiratory syncytial virus in a neonatal intensive care unit confirmed by real-time polymerase chain reaction. J. Hosp. Infect. 77, 338-342. doi: 10.1016/j.jhin.2010.12.012
Pannaraj, P. S., Tam, B., and Akan, D. (2011). Oseltamivir treatment and prophylaxis in a neonatal intensive care unit during a 2009 H1N1 influenza outbreak. J. Perinatol. 31, 487-493. doi: 10.1038/jp.2010.159

Pavia, A. T. (2011). Viral infections of the lower respiratory tract: old viruses, new viruses, and the role of diagnosis. Clin. Infect. Dis. 52(Suppl. 4), S284-S289. doi: $10.1093 / \mathrm{cid} / \mathrm{cir} 043$

Peluso, A. M., Harnish, B. A., Miller, N. S., Cooper, E. R., and Fujii, A. M. (2015). Effect of young sibling visitation on respiratory syncytial virus activity in a NICU. J. Perinatol. 35, 627-630. doi: 10.1038/jp.2015.27

Perez, G. F., Pancham, K., Huseni, S., Jain, A., Rodriguez-Martinez, C. E., Preciado, D., et al. (2015). Rhinovirus-induced airway cytokines and respiratory morbidity in severely premature children. Pediatr. Allergy Immunol. 26, 145-152. doi: 10.1111/pai.12346

Principi, N., and Esposito, S. (2004). Are we ready for universal influenza vaccination in paediatrics? Lancet Infect. Dis. 4, 75-83. doi: 10.1016/\$1473-3099(04)00926-0

Puck, J. M., Glezen, W. P., Frank, A. L., and Six, H. R. (1980). Protection of infants from infection with influenza A virus by transplacentally acquired antibody. J. Infect. Dis. 142, 844-849. doi: 10.1093/infdis/142.6.844

Reese, S. M., Thompson, M., Price, C. S., and Young, H. L. (2016). Evidence of nosocomial transmission of human rhinovirus in a neonatal intensive care unit. Am. J. Infect. Control 44, 355-357. doi: 10.1016/j.ajic.2015.10.018

Reid, A. B., Anderson, T. L., Cooley, L., Williamson, J., and Mcgregor, A. R. (2011). An outbreak of human rhinovirus species C infections in a neonatal intensive care unit. Pediatr. Infect. Dis. J. 30, 1096-1095. doi: 10.1097/INF.0b013e31822938d7

Rhedin, S., Lindstrand, A., Rotzén-Östlund, M., Tolfvenstam, T., Ohrmalm, L., Rinder, M. R., et al. (2014). Clinical utility of PCR for common viruses in acute respiratory illness. Pediatrics 133, e538-e545. doi: 10.1542/peds. 2013-3042

Rocha, G., Pissarra, S., Silva, G., and Guimares, H. (2010). Experience with oseltamivir in term and preterm newborns. Res. Gate 5, 327-331. doi: 10.3233/JPI-2010-0270

Ronchi, A., Michelow, I. C., Chapin, K. C., Bliss, J. M., Pugni, L., Mosca, F. (2014). Viral respiratory tract infections in the neonatal intensive care unit: the virion-i study. J. Pediatr. 165, 690-6. doi: 10.1016/j.jpeds.2014. 05.054

Schwab, F., Tolbert, B., Bagnato, S., and Maisels, M. J. (1983). Sibling visiting in a neonatal intensive care unit. Pediatrics 71, 835-838.

Sert, A., Yazar, A., Odabas, D., and Bilgin, H. (2010). An unusual cause of fever in a neonate: influenza A (H1N1) virus pneumonia. Pediatr. Pulmonol. 45, 734-736. doi: 10.1002/ppul.21245

Simmonds, A., Munoz, J., Montecalvo, M., Clones, B., and Lagamma, E. F. (2009). Outbreak of parainfluenza virus type 3 in a neonatal intensive care unit. Am. J. Perinatol. 26, 361-364. doi: 10.1055/s-0028-1110087

Simoes, E. A. (1999). Respiratory syncytial virus infection. Lancet 354, 847-852. doi: 10.1016/S0140-6736(99)80040-3

Simon, A., Müller, A., Khurana, K., Engelhart, S., Exner, M., Schildgen, O., et al. (2008). Nosocomial infection: a risk factor for a complicated course in children with respiratory syncytial virus infection-results from a prospective multicenter german surveillance study. Int. J. Hyg. Environ. Health 211, 241-250. doi: 10.1016/j.ijheh.2007.07.020

Singh-Naz, N., Willy, M., and Riggs, N. (1990) Outbreak of parainfluenza virus type 3 in a neonatal nursery. Pediatr. Infect. Dis. J. 9, 31-33 doi: 10.1097/00006454-199001000-00007

Smit, P. M., Pronk, S. M., Kaandorp, J. C., Weijer, O., Lauw, F. N., Smits, P. H., et al. (2013). RT-PCR detection of respiratory pathogens in newborn children admitted to a neonatal medium care unit. Pediatr. Res. 73, 355-361. doi: 10.1038/pr.2012.176

Solheim, K., and Spellacy, C. (1988). Siblings visitation: effects on newborn infection rates. J. Obstet. Gynecol. Neonatal Nurs. 17, 43-48. doi: 10.1111/j.1552-6909.1988.tb00413.x

Steiner, M., Strassl, R., Straub, J., Böhm, J., Popow-Kraupp, T., and Berger, A. (2012). Nosocomial rhinovirus infection in preterm infants. Pediatr. Infect. Dis. J. 31, 1302-1304. doi: 10.1097/INF.0b013e31826ff939

Tellier, R. (2009). Aerosol transmission of influenza A virus: a review of new studies. J. R. Soc. Interface 6(Suppl. 6):S783-S790. doi: 10.1098/rsif.2009.0302.focus 
Tsagris, V., Nika, A., Kyriakou, D., Kapetanakis, I., Harahousou, E., Stripeli, F., et al. (2012). Influenza A/H1N1/2009 outbreak in a neonatal intensive care unit. J. Hosp. Infect. 81, 36-40. doi: 10.1016/j.jhin.2012. 02.009

van Benten, I., Koopman, L., Niesters, B., Hop, W., van Middelkoop, B., de Waal, L., et al. (2003). Predominance of rhinovirus in the nose of symptomatic and asymptomatic infants. Pediatr. Allergy Immunol. 14, 363-370. doi: 10.1034/j.1399-3038.2003.00064.x

van den Berg, J. P., Westerbeek, E. A., Berbers, G. A., van Gageldonk, P. G., van der Klis, F. R., and van Elburg, R. M. (2010). Transplacental transport of igg antibodies specific for pertussis, diphtheria, tetanus, haemophilus influenzae type $b$, and neisseria meningitidis serogroup $C$ is lower in preterm compared with term infants. Pediatr. Infect. Dis. J. 29, 801-805. doi: 10.1097/INF.0b013e3181dc4f77

van Piggelen, R. O., van Loon, A. M., Krediet, T. G., and Verboon-Maciolek, M. A. (2010). Human rhinovirus causes severe infection in preterm infants. Pediatr. Infect. Dis. J. 29, 364-365. doi: 10.1097/INF.0b013e3181c6 e60f

Verboon-Maciolek, M. A., Krediet, T. G., Gerards, L. J., Fleer, A., and van Loon, T. M. (2005). Clinical and epidemiologic characteristics of viral infections in a neonatal intensive care unit during a 12-year period. Pediatr. Infect. Dis. J. 24, 901-904. doi: 10.1097/01.inf.0000180471.03702.7f

Vij, N. K., Stryker, C. C., Esper, F. P., Jacobs, M. R., and Gonzalez, B. E. (2011). Influenza A/H1N1/09-10 infections in a NICU during the 20092010 H1N1 pandemic. Pediatrics 128, e1297-e1301. doi: 10.1542/peds. 2011-0219

Visser, A., Delport, S., and Venter, M. (2008). Molecular epidemiological analysis of a nosocomial outbreak of respiratory syncytial virus associated pneumonia in a kangaroo mother care unit in south africa. J. Med. Virol. 80, 724-732. doi: $10.1002 /$ jmv. 21128

Wegzyn, C., Toh, L. K., Notario, G., Biguenet, S., Unnebrink, K., Park, C., et al. (2014). Safety and effectiveness of palivizumab in children at high risk of serious disease due to respiratory syncytial virus infection: a systematic review. Infect. Dis. Ther. 3, 133-158. doi: 10.1007/s40121-014-0046-6

Whitley, R. J., and Monto, A. S. (2006). Prevention and treatment of influenza in high-risk groups: Children, pregnant women, immunocompromised hosts, and nursing home residents. J. Infect. Dis. 194(Suppl. 2):S133-S138. doi: $10.1086 / 507548$

Wilkinson, D. J., Buttery, J. P., and Andersen, C. C. (2006). Influenza in the neonatal intensive care unit. J. Perinatol. 26, 772-776. doi: $10.1038 /$ sj.jp.7211625

Woo, P. C., Chiu, S. S., Seto, W. H., and Peiris, M. (1997). Cost-effectiveness of rapid diagnosis of viral respiratory tract infections in pediatric patients. J. Clin. Microbiol. 35, 1579-1581.

Woods, C. R., and Abramson, J. S. (2005). The next influenza pandemic: will we be ready to care for our children? J. Pediatr. 147, 147-155. doi: 10.1016/j.jpeds.2005.04.066

Wooltorton, E. (2004). Oseltamivir (Tamiflu) unsafe in infants under 1 year old. CMAJ 170:336

Zinna, S., Lakshmanan, A., Tan, S., McClaughry, R., Clarkson, M., Soo, S. et al. (2016). Outcomes of nosocomial viral respiratory infections in high-risk neonates. Pediatrics 138: e20161675. doi: 10.1542/peds.2016-1675

Conflict of Interest Statement: The authors declare that the research was conducted in the absence of any commercial or financial relationships that could be construed as a potential conflict of interest.

Copyright (c) 2018 Pichler, Assadian and Berger. This is an open-access article distributed under the terms of the Creative Commons Attribution License (CC BY). The use, distribution or reproduction in other forums is permitted, provided the original author(s) and the copyright owner(s) are credited and that the original publication in this journal is cited, in accordance with accepted academic practice. No use, distribution or reproduction is permitted which does not comply with these terms. 